Vol. 17 (2008): 367-375.

\title{
Effect of osmotic dehydration in fructose, sucrose and fructooligosaccharide solutions on the content of saccharides in plums and apples and their energy value
}

\author{
Robert Klewicki* and Małgorzata Uczciwek \\ Institute of Chemical Technology of Food, Technical University of Lodz, 90-924 Lodz, \\ 4/10 Stefanowskiego Street, Poland, *e-mail: robertkl@p.lodz.pl
}

\begin{abstract}
Plums (Najbolia and Stanley) and apples (Idared) were subjected to osmotic dehydration in $50 \%$ solutions of fructose, sucrose and fructooligosaccharides (FOS) at 22,40 and $60{ }^{\circ} \mathrm{C}$ for 24 hours. The content of fructooligosaccharides, sucrose and monosaccharides in dried material was determined. Plums osmosed in fructose contained from $22.3 \% \mathrm{w} / \mathrm{w}$ to $29.6 \% \mathrm{w} / \mathrm{w}$ of this saccharide depending on the process temperature. The content of sucrose in plums and apples varied from $18.6 \% \mathrm{w} / \mathrm{w}$ to $30.4 \% \mathrm{w} / \mathrm{w}$ after using sucrose as osmotic agent. Material processed at $40{ }^{\circ} \mathrm{C}$ was characterised by the highest content of FOS: $22.6-24.7 \%$ $\mathrm{w} / \mathrm{w}$ in plums (nystose as osmotic agent) and $13.7 \% \mathrm{w} / \mathrm{w}$ in apples (FOS preparation as osmotic agent). The partial replacement of sucrose and monosaccharides by fructooligosaccharides reduced the energy value of carbohydrates in dried material by $12-37 \%$ depending on the process conditions.
\end{abstract}

Key-words: fruits, carbohydrates, osmotic dehydration, energy value

\section{Introduction}

Osmotic dehydration is a preservation technique that is often used as a pre-treatment to improve the quality of conventional dried products (Monnerat et al. 2006). This kind of dewatering (with hypertonic aqueous solutions) has been proposed as a method to obtain partially dehydrated fruits and vegetables, which can be included in foods such as ice-cream, desserts, yogurt, dairy, cereals, confectionery and bakery products (Torreggiani and Bertolo 2001, 
Mandala et al. 2005). One of the most popular osmotic agents for fruits is sucrose because of it's low cost, but other agents such as glucose or concentrated fruit juices, are also used (Mandala et al. 2005, Rastogi et al. 2002). As osmotic dewatering is a simultaneous counter-current mass transfer process (water diffusion into the osmotic solution, a solute transfer to the processed material and a leaching out of the food's own solutes) there are many changes in chemical composition of food after osmotic treatment (Lewicki and Porzecka-Pawlak 2005, Sablani et al. 2002). As sucrose or monosaccharides are used, increase in the content of these carbohydrates in the material is an inevitable after-effect which makes the product more calorific. In order to reduce the energy value of dried products fructooligosaccharides can be used as an osmotic agent.

Fructooligosaccharides consist of fructose (the dominant carbohydrate in the chains) and glucose. As a rule a degree of polymerisation of FOS is lower than 7. Short-chain fructooligosaccharides naturally occur in some plants (i.e., onion, garlic, wheat) but they are also produced on a commercial scale from sucrose using fructosyltransferase, or from inulin (polymer consisting of fructose) by partial hydrolysis using inulinase (Bornet et al. 2002).

Fructooligosaccharides, to a large extent, are not hydrolysed in the upper intestine and reach the colon where bifidobacteria and lactobacilli (probiotics) ferment oligosaccharides to organic acids (lactic, acetic and short chain fatty acids), hydrogen peroxides and other inhibitory compounds swhich suppress growth of pathogenic microflora (Bovee-Oudenhoven et al. 2003). In addition, the microbial fermentation leads to a loss of energy for human. The energy value of FOS depends on the length of the chains but does not exceed $10 \mathrm{kJg}^{-1}$, the calorific value for sucrose amounts to $17 \mathrm{kJg}^{-1}$ (Linden and Lorient 1999). Thus, replacing sucrose with fructooligosaccharides in osmotic solutions may be beneficial to human health.

The aim of our study was to determine the amount of fructooligosaccharides and other carbohydrates occurring in dried apples and plums after osmotic dewatering at different temperatures using fructose, sucrose and FOS as osmotic agents.

\section{Materials and methods}

\section{Materials}

Najbolia and Stanley plums and Idared apples were purchased from a local market. In the case of plums each fruit was cut into eight pieces (wedgeshaped). Apples were cut into cubes of $1 \mathrm{~cm}$. Fructose (POCh, Gliwice, Poland), sucrose (Sugar factory in Werbkowice, Poland), nystose and FOS preparation containing nystose (28.0\% of DM [dry matter]), kestose $(23.7 \%$ of DM), sucrose (12.1\% of DM), fructose $(2.6 \%$ of DM) and glucose (33.6\% of DM) (Polfarmex, Kutno, Poland) were used as osmotic agents.

\section{Dewatering}

Each sample $(8.5 \pm 0.5 \mathrm{~g}$ apples or $10.5 \pm 0.5 \mathrm{~g}$ plums $)$ was submerged in an osmotic solution ( $50^{\circ} \mathrm{Brix} ; 22$ ${ }^{\circ} \mathrm{C}, 40{ }^{\circ} \mathrm{C}$ or $60^{\circ} \mathrm{C}$ ) placed in a hermetic container $\left(100 \mathrm{dm}^{3}\right)$. For osmotic dehydration of plums the fructose, sucrose and nystose solutions were used. In the case of apples the sucrose and FOS preparation solutions were used. The fruit/solution ratio was 1:2 w/w. The containers were placed in dryers and kept at $22^{\circ} \mathrm{C}, 40^{\circ} \mathrm{C}$ or $60^{\circ} \mathrm{C}$ for $24 \mathrm{~h}$. This time was considered to be sufficient for the material to reach equilibrium with a carbohydrate-water solution (Sablani and Rahman 2003, Rahman et al. 2001, Parjoko Rahman et al. 1996, Silveira et al. 1996). Next, in order to remove a surface solution samples were blotted with filter paper. Each experiment was performed in triplicate.

\section{Analyses}

The concentration of fructooligosaccharides and other carbohydrates in the dried material and syrups was determined by HPLC. Before HPLC analysis extraction of sugars from the dried material was performed. Water $(40 \mathrm{ml})$ and $\mathrm{CaCO}_{3}(0.5 \mathrm{~g})$ was 
Vol. 17 (2008): 367-375.

added to each sample ( $3 \mathrm{~g})$ and boiled. Calcium carbonate prevented the carbohydrate hydrolysis from happening. Next, the solutions were cooled down, kept at $22{ }^{\circ} \mathrm{C}$ for 15 minutes and filtered.

The osmotic solutions were tested for carbohydrates after diluting the samples ( $3 \mathrm{~g}$ ) with water to $50 \mathrm{ml}$ and filtering.

HPLC analyses were performed using Aminex HPX87C column of $0.78 \times 30 \mathrm{~cm}($ Bio-Rad) and an RI detector (Knauer). The elution medium was water at a flow rate of $0.5 \mathrm{ml} \mathrm{min}{ }^{-1}$. The column was kept at $85^{\circ} \mathrm{C}$. The concentration of carbohydrates was proportional to the area calculated for each peak with an internal standard.

The content of DM in fruits (before and after osmotic treatment) was determined gravimetrically at $102{ }^{\circ} \mathrm{C} \pm 2{ }^{\circ} \mathrm{C}$ in an oven to constant weight.

Standard deviation was calculated and statistical analysis (Duncan's multiple range test) of the results was carried out using ANOVA (StatSoft, 1995).

\section{Results and discussion}

Taking into consideration the content of saccharides in the initial material, the greatest differences between the apples and the plums occurred in the case of sucrose - from $1.3 \% \mathrm{w} / \mathrm{w}$ in the apples to nearly $9.5 \% \mathrm{w} / \mathrm{w}$ in the plums of Stanley variety (Table 1). The plums also contained over twice as much glucose as the apples did. In turn, the apples were characterized by a greater content of fructose (over $7 \% \mathrm{w} / \mathrm{w}$ ) than were the plums.

The plums used for the experiments, apart from a different content of particular saccharides, were also characterized by a different content of dry matter $-17.2 \% \mathrm{w} / \mathrm{w}$ in the case of Stanley variety and $19.8 \% \mathrm{w} / \mathrm{w}$ in the case of Najbolia variety. Differences in the dry matter content were also observed in the material after 24-hour osmotic drying (Table 2). The differences reached up from 3 to $4 \% \mathrm{w} / \mathrm{w}$

Table 1. The content of saccharides in fresh plums and apples.

\begin{tabular}{lcccc}
\hline \multirow{2}{*}{ Fruit } & \multicolumn{4}{c}{ Content of saccharides $(\% \mathrm{w} / \mathrm{w})$} \\
\cline { 2 - 5 } & Sucrose & Fructose & Glucose & Higher saccharides \\
\hline Plum Najbolia & 8.35 & 2.94 & 4.05 & 0.59 \\
Plum Stanley & 9.44 & 1.51 & 3.61 & 0.75 \\
Apple Idared & 1.30 & 7.08 & 1.60 & 0.05 \\
\hline
\end{tabular}

Table 2. The content of dry matter (DM) in plums after osmotic dewatering ( 24 hours) in different hypertonic solutions, at various temperatures.

\begin{tabular}{lcccc}
\hline \multirow{2}{*}{ Fruit } & Temperature $\left({ }^{\circ} \mathrm{C}\right)$ & \multicolumn{3}{c}{$\mathrm{DM}^{1)}(\% \mathrm{w} / \mathrm{w})$} \\
\cline { 3 - 5 } & & $50 \%$ nystose & $50 \%$ sucrose & $50 \%$ fructose \\
\hline Plum Najbolia $^{2)}$ & 22 & $32.8 \pm 1.3$ & $36.4 \pm 0.9$ & $40.1 \pm 1,4$ \\
& 40 & $40.8 \pm 0.8$ & $40.9 \pm 1.2$ & $42.7 \pm 1,3$ \\
& 60 & $42.4 \pm 0.8$ & $43.4 \pm 1.1$ & $43.4 \pm 1.0$ \\
Plum Stanley ${ }^{2)}$ & 22 & $32.6 \pm 1.0$ & $34.0 \pm 0.6$ & $40.2 \pm 0.9$ \\
& 40 & $39.6 \pm 1.7$ & $40.7 \pm 0.9$ & $39.7 \pm 1.2$ \\
& 60 & $38.0 \pm 0.9$ & $42.4 \pm 1.4$ & $41.2 \pm 0.8$ \\
\hline
\end{tabular}

1) Mean value \pm standard deviation

${ }^{2)}$ Initial content of dry matter: $19.8 \% \mathrm{w} / \mathrm{w}$ (in Najbolia), $17.2 \% \mathrm{w} / \mathrm{w}$ (in Stanley) 


\section{AGRICULTURAL AND FOOD SCIENCE}

\section{Klewicki, R. \& Uczciwek, M. Osmotic dehydration of fruit}

Table 3. The content of dry matter (DM) in apples after osmotic dewatering (24 hours) in different hypertonic solutions, at various temperatures.

\begin{tabular}{lccc}
\hline \multirow{2}{*}{ Fruit } & \multicolumn{2}{c}{$\mathrm{DM}^{1)}(\% \mathrm{w} / \mathrm{w})$} \\
\hline Apple Idared $^{2)}$ & 22 & $50 \%$ FOS & $50 \%$ sucrose \\
\cline { 3 - 4 } & 40 & $32.7 \pm 0.8$ & $34.3 \pm 1.0$ \\
& 60 & $38.9 \pm 1.0$ & $37.9 \pm 0.7$ \\
& & $40.3 \pm 1.1$ & $39.8 \pm 0.9$ \\
\hline
\end{tabular}

\footnotetext{
${ }^{1)}$ Mean value \pm standard deviation

2) Initial content of dry matter: $13.9 \% \mathrm{w} / \mathrm{w}$
}

for the plums of different varieties dried in the same conditions.

A comparison of the content of dry matter in the plums and apples (Tables 2 and 3) after osmotic drying shows that, in the case of plums, in particular of Najbolia variety, higher values of this parameter $\left(43.4 \% \mathrm{w} / \mathrm{w}\right.$ at $50{ }^{\circ} \mathrm{C}$ using $50 \%$ sucrose) can be obtained after 24 hours, compared to the apples $(39.8 \% \mathrm{w} / \mathrm{w}$ in identical conditions). However, due to a lower initial content of dry matter in the apples (less than $14 \% \mathrm{w} / \mathrm{w}$ ) compared to the plums $(17.2$ and $19.8 \% \mathrm{w} / \mathrm{w})$, an increase in the content of dry matter in the apples is considerably higher (Fig. 1) and is from $147 \%$ at $22{ }^{\circ} \mathrm{C}$ to $186 \%$ at 60 ${ }^{\circ} \mathrm{C}$ after drying it in a $50 \%$ sucrose solution. In the case of plums dehydrated in analogous conditions, an increase in the content of dry matter varied from
$84 \%$ to $119 \%$ for Najbolia variety and from $98 \%$ to $146 \%$ for Stanley variety.

The juxtaposition of the increases in the content of dry matter in the plums dehydrated in solutions of pure substances of different molecular weights (mono-, di- and tetrasaccharide) shows that at a low dehydration temperature $\left(22^{\circ} \mathrm{C}\right)$ the size of osmoactive substance particles has an influence on solid gain. In the case of Najbolia plums the increase in the content of dry matter after osmotic drying in 50\% nystose, $50 \%$ sucrose and $50 \%$ fructose amounted to 66,84 and $102 \%$, respectively, while in the case of Stanley plums: 89,98 and $134 \%$. These differences disappeared after higher temperatures were used $\left(40\right.$ and $60^{\circ} \mathrm{C}$ ).

The effect of obtaining a higher content of dry matter in the plums dehydrated by means of
Fig.1 Solids gain (mean value \pm standard deviation) of plums and apples after 24-hour dehydration in fructose, sucrose and fructooligosaccharides [nystose or FOS preparation: nystose $(28.0 \%$ of DM), kestose (23.7\% of DM), sucrose (12.1\% of DM), fructose $(2.6 \%$ of DM) and glucose $(33.6 \%$ of DM)] at different temperatures in $50^{\circ} \mathrm{Bx}$ solutions. The syrup-fruit mass ratio: $2 / 1$.

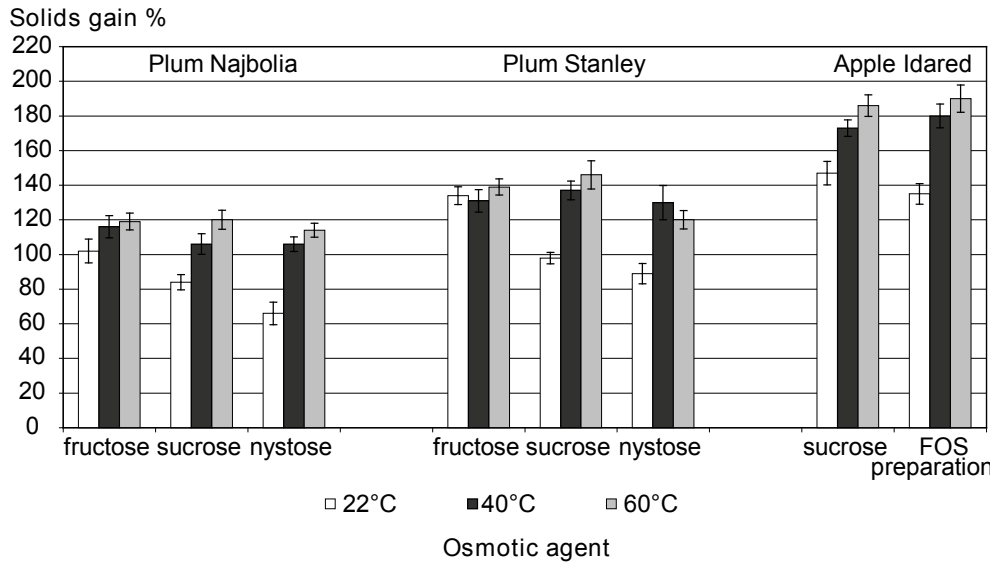


Vol. 17 (2008): 367-375.

an osmotic agent of a smaller molecular weight (fructose) in comparison with an osmotic agent of a high molecular weight (nystose) can be attributed to the fact that small molecules have a better ability to penetrate into the material during the soaking observed in particular at lower temperatures. This is shown by the comparison of the content of the main saccharides in dried fruit and their sums in the whole system (fruit + solution) presented in Table 4. After drying at $22{ }^{\circ} \mathrm{C}$ in a $50 \%$ fructose solution, the concentration of this saccharide in Najbolia was $22.3 \% \mathrm{w} / \mathrm{w}$. The concentration of nystose was only $14.4 \% \mathrm{w} / \mathrm{w}$ (after drying in a $50 \%$ solution of this saccharide). Taking the initial concentration of fructose in Najbolia $(2.9 \% \mathrm{w} / \mathrm{w})$ and the absence of nystose, an increase in the fructose concentration by $19.4 \% \mathrm{w} / \mathrm{w}$ was obtained, compared to $14.4 \% \mathrm{w} / \mathrm{w}$ in the case of nystose. A similar situation can be observed for Stanley plums. The content of fructose after drying was $22.3 \% \mathrm{w} / \mathrm{w}$, while that of nystose was $16.8 \% \mathrm{w} / \mathrm{w}$. With the initial fructose content in plums of the Stanley variety of $1.5 \% \mathrm{w} / \mathrm{w}$, the difference in the increment of concentration is 20.8 to 16.8 in favour of fructose.

In the case of the capability of sucrose to migrate into plums, the situation is more complicated due to a high content of sucrose in the initial material (over 8 to $9 \% \mathrm{w} / \mathrm{w}$ ), which undoubtedly limited the amount of saccharose absorbed from the outside. However, taking apples as an example, it can be seen that sucrose has also an ability to migrate into the fruit flesh in considerable quantities. The concentration of this saccharide in the osmotically dried material was $18.6 \% \mathrm{w} / \mathrm{w}$ (with an initial content of $1.3 \% \mathrm{w} / \mathrm{w})$, which results in an increase in the content by $17.3 \% \mathrm{w} / \mathrm{w}$.

The ability of both mono- and disaccharides (sucrose) to migrate in large quantities into the material subjected to osmotic drying is of course undesirable from the point of view of the energy value of the products obtained. The content of fructose and sucrose in the dehydrated material varied from 20 to $30 \% \mathrm{w} / \mathrm{w}$ when concentrated solutions of the substances mentioned were used. The use of nystose as an osmotic agent limited the fraction of high energy saccharides in the processed fruit. In the worst case the total concentration of monosac- charides and sucrose did not exceed $18 \% \mathrm{w} / \mathrm{w}$, and in most cases it amounted to about $10 \% \mathrm{w} / \mathrm{w}$.

Assuming energy values to be $17 \mathrm{kJg}^{-1}$ for sucrose, glucose and fructose, and $10 \mathrm{kJg}^{-1}$ for nystose and kestose (Linden and Lorient 1999), a diagram of the dependence of the total energy value of the main saccharides contained in $100 \mathrm{~g}$ of the dried fruit on the conditions of osmotic drying (osmoactive substance, temperature) was obtained (Fig. 2). A reduction of the energy value after dehydration performed in nystose solutions in comparison with dewatering performed by means of fructose and sucrose can be seen. This effect occurs for all the temperatures applied. Depending on the dewatering variant the reduction of the energy value was from 15 to $37 \%$. In one case $\left(60{ }^{\circ} \mathrm{C}\right.$, nystose as an osmotic agent) a reduction of the calorific value by $48 \%$ was obtained; however, it was also related to a slightly lower content of the dry matter in the material after drying $(38.0 \% \mathrm{w} / \mathrm{w})$ in comparison with the remaining samples (from 41.2 to $43.4 \% \mathrm{w} / \mathrm{w}$ ).

It also proved beneficial to use an FOS preparation, which contains $52 \%$ of fructooligosaccharides. The reduction of the calorific value of carbohydrates in $100 \mathrm{~g}$ dried apples was from 12 to $23 \%$ and was lower than that of the plums dehydrated in pure nystose solutions due to the presence of saccharides of a higher energy value, first of all of sucrose $(12.1 \% \mathrm{w} / \mathrm{w})$ and glucose $(33.6 \% \mathrm{w} / \mathrm{w})$ in FOS preparations.

The use of this type of preparations obtained from sucrose by means of enzymatic transglycosylation is justified economically to a larger extent (it is possible to produce FOS preparations from sucrose at a relatively low cost (Król and Klewicki 2005)) than using pure solutions of fructooligosaccharides (in this case: nystose obtained by means of crystallization from sucrose hydrolysates).

The lower content of nystose in the plums and of nystose and kestose in the apples after drying at $60{ }^{\circ} \mathrm{C}$ (Table 4) can be associated with the process of hydrolysis of fructooligosaccharides occurring during dehydration. A similar effect (yet of a smaller intensity) was observed in the case of sucrose. The content of fructooligosaccharides in the plums after dehydration at $60{ }^{\circ} \mathrm{C}$ is over $30 \%$ smaller than in the case of dehydration at $40{ }^{\circ} \mathrm{C}$. In particular, 


\section{Klewicki, R. \& Uczciwek, M. Osmotic dehydration of fruit}

in the case of Najbolia an approx. $30 \%$ decrease in the FOS content in the fruit dehydrated after the elevation of the temperature from $40{ }^{\circ} \mathrm{C}$ to $60{ }^{\circ} \mathrm{C}$ correlates well with an approx. $30 \%$ decrease in the total amount of fructooliogosaccharides in the fruit-syrup system, before and after osmotic drying. As for the Stanley plums the situation was less clear, where a greater decrease in the FOS content was observed after drying (34\%) with a smaller reduction of the total amount of fructooligosaccharides in the system $(25 \%)$.

The hydrolysis of fructooligosaccharides observed at $60{ }^{\circ} \mathrm{C}$ results from the activity of hydrogen ions in the medium ( $\mathrm{pH}$ of the syrups after 24 hours reached values below 4$)$. It results from the studies by Gałązka et al. (2004) that in the acid medium it is kestose and nystose that decompose fastest of all fructans. In this process the fructose residue is detached from the FOS particle. The highest increase in the fructose content (of monosaccharides and sucrose - hydrolysis products) was obtained in the present studies as well (Table 4). Bolin et al. (1983) also indicate the acid hydrolysis as the main cause of the decrease in the sucrose content during the osmotic drying of fruit. The hydrolysis of saccharides may to a certain degree be caused by the activity of enzymes in fruit. For instance, Viberg and Sjöholm (1998) point to the activity of invertase as the significant cause of the reduction of sucrose content in strawberries subjected to osmotic drying.

In general, the decomposition of fructooligosaccharides is an unfavourable phenomenon since the amount of monosaccharides and sucrose in the syrup increases, which results in the increase in energy value of the product and renders it difficult to maintain a similar composition of particular batches of dried fruit. A clearly visible phenomenon of FOS hydrolysis after 24 hours of dehydration shows that problems with the varying composition of the hypertonic solution will occur after repeated use of the solution of a temperature of 60 ${ }^{\circ} \mathrm{C}$ (this is certain if the total time of dehydration in the particular charges approaches 24 hours). To be protected against these undesirable changes, it is favourable to use a temperature of $40^{\circ} \mathrm{C}$. Of the three temperatures used, it is at $40{ }^{\circ} \mathrm{C}$ that the highest content of FOS was obtained; $22.6 \% \mathrm{w} / \mathrm{w}$ for Stanley variety and $24.7 \% \mathrm{w} / \mathrm{w}$ for Najbolia variety. The content obtained in the apples was $13.7 \% \mathrm{w} / \mathrm{w}$; however, with an initial concentration of fructooligosaccharides in the syrup being twice as low (Table 4). After 24 hours no decrease in the total content of FOS in the system was observed. The absence of hydrolysis is also confirmed by similar total amounts of sucrose, glucose and fructose in the fruit (apple or plum) -syrup system before and after osmotic drying.
Fig.2 Energy value of sugars (mean value \pm standard deviation) contained in plums and apples dehydrated ( 24 hours) in fructose, sucrose and fructooligosaccharides [nystose or FOS preparation: nystose $(28.0 \%$ of DM), kestose $(23.7 \%$ of DM), sucrose ( $12.1 \%$ of DM), fructose $(2.6 \%$ of DM) and glucose (33.6\% of DM)] at different temperatures in $50^{\circ} \mathrm{Bx}$ solutions. The syrup-fruit mass ratio: $2 / 1$. A, B, a, b, c, $\alpha, \beta, \chi$ - values with different letters (for given temperature and fruit) differ significantly at $p<0.05$.

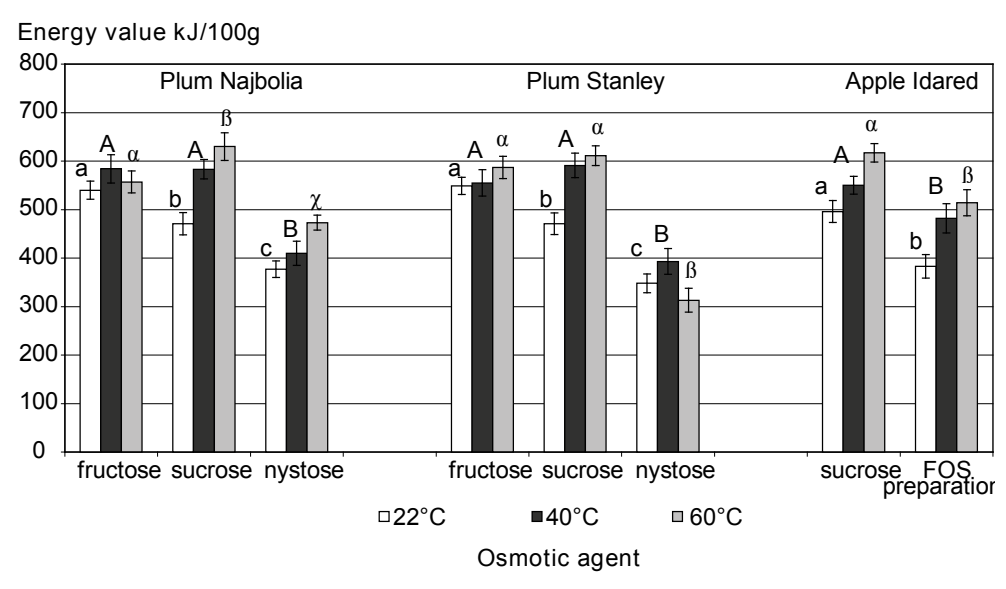


Vol. 17 (2008): 367-375.

Table 4. The total content of carbohydrates in fruit and hypertonic solution (in fresh weight) before (TB) and after (TA) osmotic dewatering at various temperatures and the final content of carbohydrates in dried material (C, expressed as a weight percentage). Process parameters: $50 \% \mathrm{w} / \mathrm{w}$ osmotic solution (fructose, sucrose, nystose or FOS preparation ${ }^{1)}$ ), time -24 hours.

\begin{tabular}{|c|c|c|c|c|c|c|c|c|c|c|c|c|c|c|}
\hline \multirow[t]{3}{*}{ Fruit } & \multirow{3}{*}{$\begin{array}{l}\text { Syrup } \\
\text { Osmotic agent }\end{array}$} & \multirow[b]{3}{*}{$\left({ }^{\circ} \mathrm{C}\right)$} & \multicolumn{12}{|c|}{ Content of carbohydrates } \\
\hline & & & \multicolumn{3}{|c|}{ sucrose } & \multicolumn{3}{|c|}{ glucose } & \multicolumn{3}{|c|}{ fructose } & \multicolumn{3}{|c|}{$\mathrm{FOS}^{2)}$} \\
\hline & & & $\begin{array}{l}\text { TB } \\
(\mathrm{g})\end{array}$ & $\begin{array}{l}\text { TA } \\
(\mathrm{g})\end{array}$ & $\begin{array}{l}\mathrm{C} \\
(\%)\end{array}$ & $\begin{array}{l}\text { TB } \\
(\mathrm{g})\end{array}$ & $\begin{array}{l}\text { TA } \\
(\mathrm{g})\end{array}$ & $\begin{array}{l}\mathrm{C} \\
(\%)\end{array}$ & $\begin{array}{l}\text { TB } \\
(\mathrm{g})\end{array}$ & $\begin{array}{l}\text { TA } \\
(\mathrm{g})\end{array}$ & $\begin{array}{l}\mathrm{C} \\
(\%)\end{array}$ & $\begin{array}{l}\text { TB } \\
(\mathrm{g})\end{array}$ & $\begin{array}{l}\text { TA } \\
(\mathrm{g})\end{array}$ & $\begin{array}{l}\mathrm{C} \\
(\%)\end{array}$ \\
\hline Plum & Fructose & 22 & 0.82 & 0.84 & 6.12 & 0.39 & 0.35 & 3.35 & 10.2 & 9.74 & 22.3 & - & - & - \\
\hline \multirow[t]{8}{*}{ Najbolia } & & 40 & 0.83 & 0.71 & 3.37 & 0.40 & 0.48 & 2.36 & 10.3 & 9.43 & 28.6 & - & - & - \\
\hline & & 60 & 0.93 & 0.69 & 2.23 & 0.44 & 0.67 & 2.23 & 11.6 & 10.8 & 28.3 & - & - & - \\
\hline & Sucrose & 22 & 11.4 & 11.1 & 20.4 & 0.42 & 0.58 & 4.24 & 0.30 & 0.40 & 3.08 & - & - & - \\
\hline & & 40 & 10.9 & 10.1 & 27.6 & 0.40 & 0.71 & 3.68 & 0.29 & 0.57 & 3.02 & - & - & - \\
\hline & & 60 & 11.5 & 9.15 & 25.7 & 0.40 & 1.49 & 6.14 & 0.29 & 1.28 & 5.20 & - & - & - \\
\hline & Nystose & 22 & 0.83 & 1.12 & 6.12 & 0.40 & 0.43 & 3.86 & 0.29 & 0.39 & 3.73 & 9.96 & 10.0 & 14.4 \\
\hline & & 40 & 0.83 & 1.01 & 3.52 & 0.40 & 0.50 & 2.54 & 0.29 & 0.48 & 3.52 & 10.0 & 10.2 & 24.7 \\
\hline & & 60 & 0.89 & 1.92 & 4.57 & 0.42 & 0.95 & 4.38 & 0.23 & 2.53 & 8.95 & 10.8 & 7.66 & 16.9 \\
\hline Plum & Fructose & 22 & 0.86 & 1.07 & 7.04 & 0.41 & 0.34 & 2.98 & 10.6 & 9.63 & 22.3 & - & - & - \\
\hline \multirow[t]{8}{*}{ Stanley } & & 40 & 0.93 & 0.89 & 2.60 & 0.44 & 0.35 & 1.16 & 10.6 & 10.7 & 28.9 & - & - & - \\
\hline & & 60 & 0.87 & 0.79 & 2.96 & 0.42 & 0.53 & 1.98 & 10.9 & 9.66 & 29.6 & - & - & - \\
\hline & Sucrose & 22 & 15.5 & 12.6 & 22.8 & 0.57 & 0.58 & 3.51 & 0.41 & 0.24 & 1.42 & - & - & - \\
\hline & & 40 & 11.6 & 11.0 & 30.4 & 0.42 & 0.61 & 2.71 & 0.31 & 0.34 & 1.65 & - & - & - \\
\hline & & 60 & 10.4 & 7.39 & 25.6 & 0.38 & 1.18 & 5.76 & 0.27 & 0.93 & 4.58 & - & - & - \\
\hline & Nystose & 22 & 0.95 & 1.09 & 5.67 & 0.45 & 0.44 & 3.21 & 0.33 & 0.22 & 1.71 & 11.5 & 9.21 & 16.8 \\
\hline & & 40 & 0.88 & 1.38 & 6.51 & 0.42 & 0.43 & 1.87 & 0.30 & 0.33 & 1.42 & 10.7 & 10.9 & 22.6 \\
\hline & & 60 & 0.90 & 1.31 & 4.09 & 0.43 & 0.48 & 2.19 & 0.31 & 1.31 & 3.36 & 10.8 & 8.01 & 14.9 \\
\hline Apple & Sucrose & 22 & 8.05 & 7.99 & 18.6 & 0.10 & 0.49 & 3.02 & 0.44 & 0.51 & 7.55 & - & - & - \\
\hline \multirow[t]{5}{*}{ Idared } & & 40 & 7.95 & 7.78 & 25.7 & 0.10 & 0.44 & 2.33 & 0.44 & 0.54 & 4.33 & - & - & - \\
\hline & & 60 & 8.01 & 6.48 & 24.8 & 0.11 & 1.06 & 4.68 & 0.45 & 1.18 & 6.81 & - & - & - \\
\hline & FOS preparation & 22 & 1.04 & 1.12 & 4.56 & 2.67 & 2.50 & 6.18 & 0.57 & 0.65 & 7.66 & 4.15 & 4.22 & 7.07 \\
\hline & & 40 & 1.02 & 1.09 & 4.80 & 2.62 & 2.48 & 9.96 & 0.56 & 0.69 & 5.52 & 4.07 & 4.14 & 13.7 \\
\hline & & 60 & 1.02 & 1.39 & 5.64 & 2.61 & 2.65 & 11.8 & 0.55 & 1.19 & 5.64 & 4.04 & 3.12 & 12.2 \\
\hline
\end{tabular}

1) FOS preparation - nystose (28.0\% of DM), kestose (23.7\% of DM), sucrose (12.1\% of DM), fructose (2.6\% of DM) and glucose $(33.6 \%$ of DM)

${ }^{2)}$ FOS - sum of nystose and kestose 
The use of the drying temperature of $40{ }^{\circ} \mathrm{C}$ can also be favourable from the point of view of the stability of other substances contained in fruit. The investigations carried out by Torreggiani (1993) showed that the use of a temperature of over 45 ${ }^{\circ} \mathrm{C}$ contributes to the intensification of enzymatic browning processes and the loss of flavours.

The content of oligosaccharides in the dry matter of the material subjected to osmotic dehydration was from 50 to $70 \% \mathrm{w} / \mathrm{w}$ depending on the process conditions. This value is approximately twice as high as that of the content of fructans in the onion, which is considered the richest natural source of fructooligosaccharides (Bornet et al. 2002). FOS-rich dried fruits offer a possibility to consume fructooligosaccharides with products of desirable sensory properties, which can be of special significance for persons who do not tolerate specific organoleptic properties of the onion, the garlic (their second natural source in respect of the content of fructans) or chicory (bitterness). But the most important issue is that the consumption of dried fruit reach in oligosaccharides can be beneficial to human health. It is known that the daily ingestion of $2-10 \mathrm{~g}$ of FOS stimulates the growth of desirable probiotic bacteria (Mussatto and Mancilha, 2007).

\section{Conclusions}

The results obtained from this study show that osmotic drying of fruit in fructooligosaccharides solutions is a promising method for production of oligosaccharides-rich dried products characterised by a reduced energy value. It is possible to prevent the hydrolysis of fructooligosaccharides during a long-lasting process (the total time 24 hours) by lowering the dehydration temperature $\left(40^{\circ} \mathrm{C}\right)$.

Acknowledgment. This work was supported by ISAFRUIT PROJECT which is funded by the European Commission under the Thematic Priority 5 - Food Quality and Safety of the $6^{\text {th }}$ Framework Programme of RTD (Contract no. FP6-FOOD-CT-2006-016279).

\section{References}

Bolin, H.R., Huxsoll, C.C., Jackson, R., \& Ng, K.C. 1983. Effect of osmotic agents and concentration on fruit quality. Journal of Food Science 48: 202-205.

Bornet, F.R.J., Brouns, F., Tashiro, Y., \& Duvillier, V. 2002. Nutritional aspects of short-chain fructooligosaccharides: natural occurrence, chemistry, physiology and health implications. Digestive and Liver Disease 34 (suppl. 2): S111-S120.

Bovee-Oudenhoven, I.M.J., ten Bruggencate, S.J.M., Lettink-Wissink, M.L.G., \& van der Meer, R. 2003. Dietary fructo-oligosaccharides and lactulose inhibit intestinal colonisation but stimulate translocation of salmonella in rats. Gut 52: 1572-1578.

Gałązka, I., Klewicki, R., \& Grzelak, K. 2004. Hydrolysis of fructans under the conditions simulating the effect of gastric juice. Żywność 40 (suppl.): 68-76.

Król, B., \& Klewicki, R. 2005. Production of fructooligosaccharides (FOS) concentrations with various contents of oligomers using enzymatic bioconversion of sucrose. Żywność 43: 5-22.

Lewicki, P.P., \& Porzecka-Pawlak, R. 2005. Effect of osmotic dewatering on apple tissue structure. Journal of Food Engineering 66: 43-50.

Linden, G., \& Lorient, D. 1999. New ingredients in food processing. 1st ed. Cambridge: Woodhead Publishing Limited. $224 \mathrm{p}$.

Mandala, I.G., Anagnostaras, E.F., \& Oikonomou, C.K. 2005. Influence of osmotic dehydration conditions on apple air-drying kinetics and their quality characteristics. Journal of Food Engineering 69: 307-316.

Monnerat, S.M., Pizzi, T.R.M., Mauro, M.A., \& Menegalli, F.C. 2006. Concentration profiles and effective diffusion coefficient of sucrose and water in osmo-dehydrated apples. Food Research International 39: 739-748.

Mussatto, S.I., \& Mancihla, I.M. 2007. Non-digestible oligosaccharides: A review. Carbohydrate Polymers 68: 587-597.

Parjoko Rahman, M.S., Buckle, K.A., \& Perera, C.O. 1996. Osmotic dehydration kinetics of pineapple wedges using palm sugar. Food Science Technology 29: 452-459.

Rahman, M.S., Sablani, S.S., \& Al-Ibrahim, M.A. 2001. Osmotic dehydration of potato: equilibrium kinetics. Drying Technology 19: 1163-1176.

Rastogi, N.K., Raghavarao, K.S.M.S., Niranjan, K., \& Knorr, D. 2002. Recent developments in osmotic dehydration: methods to enhance mass transfer. Trends in Food Science \& Technology 13: 48-59.

Sablani, S.S., \& Rahman, M.S. 2003. Effect of syrup concentration, temperature and sample geometry on equilibrium distribution coefficients during osmotic dehydration of mango. Food Research International 36: 65-71.

Sablani, S.S., Rahman, M.S., \& Al-Sadeiri, D.S. 2002. Equilibrium distribution data for osmotic drying of apple cubes in sugar-water solution. Journal of Food Engineering 52: 193-199.

Silveira, E.T.F., Rahman, M.S., \& Buckle, K.A. 1996. Osmotic dehydration of pineapple: kinetics and product quality. Food Research International 29: 227-233.

StatSoft, 1995. Statistica. Release 5. 
Vol. 17 (2008): 367-375.

Torreggiani, D. 1993. Osmotic dehydration in fruit and vegetable processing. Food Research International 26: 59-68.

Torreggiani, D., \& Bertolo, G. 2001. Osmotic pre-treatments in fruit processing: chemical, physical and structural ef- fects. Journal of Food Engineering 49: 247-253.

Viberg, U., \& Sjöholm, I. 1998. Sucrose inversion during osmotic pre-treatment of strawberries. LebensmittelWissenschaft \& Technologie 31: 546-551. 